HEALTH PSYCHOLOGY REPORT · VOLUME 5(2), 2017 ORIGINAL ARTICLE
Paola Venuti

$1 \cdot \mathrm{A}, \mathrm{D}, \mathrm{E}, \mathrm{G}$

Arianna Bentenuto

$1 \cdot \mathrm{B}, \mathrm{E}, \mathrm{F}$

Stefano Cainelli

$1 \cdot \mathrm{A}, \mathrm{B}, \mathrm{E}$

Isotta Landi

$1 \cdot \mathrm{C}$
Ferdinando Suvini

$2 \cdot \mathrm{B}, \mathrm{G}$

Raffaella Tancredi

$2 \cdot \mathrm{B}$

Roberta Igliozzi

$2 \cdot \mathrm{B}$

Filippo Muratori

$2,3 \cdot \mathrm{A}, \mathrm{G}$

\title{
A joint behavioral and emotive analysis of synchrony in music therapy of children with autism spectrum disorders
}

\section{BACKGROUND}

Synchrony is an essential component of interactive exchanges. In mother-infant interaction, synchrony underlies reciprocity and emotive regulation. A severe lack of synchrony is indeed a core issue within the communication and interaction deficit that characterizes autism spectrum disorders (ASD) in accordance with the DSM-5 classification. Based on emerging evidence that music therapy can improve the communication and regulation ability in children with ASD, we aim to verify quantitatively whether: 1) children with ASD improve synchrony with their therapist during music therapy sessions, and 2) this ability persists in different structured contexts.

\section{PARTICIPANTS AND PROCEDURE}

Twenty-five children, aged from 4 to 6 years $(M=57.80$, $S D=16.70)$, with an autistic disorder diagnosis based on DSM IV-TR and the Autism Diagnostic Observation Schedule (ADOS), participated in the study. An observational tool for coding behaviors and emotive states of synchrony (Child Behavioral and Emotional status Code [CBEC] and Adult Behavioral and Emotional status Code $[\mathrm{ABEC}]$ ) was applied in video recorded sessions of impro- visational music therapy (IMT) for the subject-therapist pair. For each subject, we considered the 20 central minutes of the first, tenth and twentieth session of IMT. To verify the persistence of effect in a different context with a different adult, we administered and coded the interactive ADOS section (anticipation of a routine with objects) applied after session 20 of therapy.

\section{RESULTS}

During the IMT cycle, the amount of synchronic activity increases, with a significant difference from Session 1 to Session 20 in behavioral synchrony and emotional attunement. Also, the increase of synchrony is confirmed at the end of the therapy cycle as measured by an interactive ADOS section.

CONCLUSIONS

Synchrony is an effective indicator of efficacy for music therapy in children with ASD, in particular to evaluate the expansion of positive emotive exchanges.

KEY WORDS

music therapy; synchrony; observation; ASD

ORganization - 1: Observation, Diagnosis and Education Laboratory, Psychology and Cognitive Sciences Department, University of Trento, Italy · 2: IRCCS Stella Maris Foundation, Pisa, Italy · 3: University of Pisa, Italy aUthors' Contributions - A: Study design - B: Data collection - C: Statistical analysis - D: Data interpretation .

E: Manuscript preparation · F: Literature search · G: Funds collection

CORRESPONDING AUTHOR - Prof. Paola Venuti, Observation, Diagnosis and Education Laboratory, Psychology and Cognitive Sciences Department, University of Trento, Via Matteo del Ben 5, 38068 Rovereto, Italy, e-mail: paola.venuti@unitn.it

to Cite this article - Venuti, P., Bentenuto, A., Cainelli, S., Landi, I., Suvini, F., Tancredi, R., Igliozzi, R., \& Muratori, F. (2017). A joint behavioral and emotive analysis of synchrony in music therapy of children with autism spectrum disorders. Health Psychology Report, 5(2), 162-172. doi: https://doi.org/10.5114/hpr.2017.63985 


\section{BACKGROUND}

Child interaction with adults and the social environment plays a central role in early development: indeed it is the quality of interaction with a primary caregiver that is crucial for children's social (Black \& Logan, 1995; Cole, Hall, \& Radzich, 2009), emotional and cognitive growth (Bornstein \& Lamb, 2015; Leclère et al., 2014; Harrist \& Waugh, 2002). Some features of this interaction have been defined: "responsiveness" (Ainsworth, Bell, \& Stayton, 1974), "reciprocity" (Belsky, Rovine, \& Taylor, 1984), "rhythmicity", "mutuality" (Tronick, Als, \& Brazelton, 1977; Maccoby \& Martin, 1983), "turn-taking", "shared affect” (Leclère et al., 2014). The concept of the dyadic synchrony between mother (or another primary caregiver) and child underlies all these definitions; synchrony is characterized by a continuous dynamic and reciprocal adaptation of the temporal structures of behavior and emotion that are shared between interactive partners. For example, three different levels of interaction describe the mother-infant relationship: a) the behavioral level, focused on the "dyad" as an interacting system of bidirectional nature; b) the emotion-affective level, which considers the rhythm between partners and the ability of partners to show attunement to each other's rhythm; c) biological level: an emerging domain based on biological correlates of behaviorally synchronic phenomena, such as interbrain synchronization (Dumas, Nadel, Soussignan, Martinerie, \& Garnero, 2010). This paper explores the first two levels.

Observationally, the study of synchrony between interactive partners implies measuring two different domains. The first domain describes verbal and non-verbal communicative and emotional behaviors (gestures, postures, facial displays, vocalizations, gaze) of the two partners, while the second domain evaluates the coordination of exchange between partners, considering the complexity of their responses by different modalities (e.g. responding with a smile or a distress signal to a vocal production).

Thus, "synchrony describes the intricate 'dance' of multimodal signaling that occurs during short intense playful interaction" (Leclère et al., 2014, p. 3) as well as in structured therapy sessions. Such signaling builds on familiarity with the partner's behavioral repertoire and interaction rhythms. In its most basic mode, synchrony as a feature of interaction qualifies and quantifies both the mother's and the child's responsivity and their emotional capacity to respond to each other.

The emphasis on the role of parent-infant synchrony for social communication development is well motivated by the implication of dysregulated parent-child interaction when children's problematic behaviors appear. For example, autism spectrum disorder (ASD) is characterized by patterns of delay and deviance in the development of social, communicative, and cognitive skills that arise in the first years of life and can have a significant impact on the acquisition of synchrony and reciprocity (Volkmar et al., 2014)

Studies have already revealed as early indicators of autism abnormalities in eye contact, imitation, engagement/disengagement, joint attention, orienting to name, and body language (Siller \& Sigman, 2008; Dawson, 2008). All these behaviors are parts of the "affective tuning", defined by Stern (1985) as the "execution of behaviors expressing the emotional ownership of a shared affective state". This term refers to infant-caregiver emotional communication based on rhythmic similarity from the second semester of life onward. Affective tuning disturbances are important precursors of later-developing symptoms.

By challenging the development of basic behavioral synchrony, indeed children with ASD exhibit significant social, affective, and behavioral difficulties. Conversely, it may be considered whether therapy oriented at improving attunement in interaction can mitigate the atypical development of these children and whether control of synchrony may be the key to optimizing developmental outcomes and reducing ASD symptoms (Kasari, Gulsrud, Wong, Kwon, \& Locke, 2010; Baker, Messinger, Lyons, \& Grantz, 2010; Feldman, 2012; Johnson, Jones, \& Gliga, 2015; Baker et al., 2015). This option is supported by studies regarding parents' ability to promote development in children with ASD that highlighted the importance of parent-child synchronous exchange (Greenspan \& Wieder, 1999)

In this paper we discuss the bases for a treatment with children with ASD aimed at improving the child's ability to sustain a syntonic exchange with a significant adult. Especially we focus on music therapy and on its core concept of 'musical attunement' to produce moment-by-moment, responsive use of improvisational music highly sensitive and attentive to the child's expression, either musical or non-musical.

The improvisational music therapy (IMT) technique has an international consensus among the technical approaches in music therapy for children with ASD (Geretsegger et al., 2015). It is a child-centered approach that utilizes mainly non-verbal musical interaction and thus is comparable with early reciprocal interaction between mother and infant (Hughes, 1995; Holck, 2004a, 2004b; Pavlicevic, 1997; Robarts, 1996; Trolldalen, 2005). As an intervention procedure, IMT makes use of the potential for social engagement and expression of emotions occurring through improvisational music making (Geretsegger, Holck, \& Gold, 2012; Geretsegger, Elefant, Mòssler, \& Gold, 2014).

We are specifically interested in the essential principle of IMT to envelop the solitary child's actions
Synchrony in music therapy with children with $A S D$ 
Paola Venuti,

Arianna

Bentenuto,

Stefano Cainelli, Isotta Landi,

Ferdinando

Suvini,

Raffaella Tancredi,

Roberta Igliozzi,

Filippo Muratori within a fluid musical scaffolding, facilitating the structuring of a shared history of musical interaction between child and therapist and thus their musical and emotional attunement.

Improvisational music therapy is already noted for its efficacy in engaging children with ASD at their level and interest, and helping them to develop spontaneous self-expression, emotional communication and social interaction (Alvin, 1978; Edgerton, 1994; Gold, Wigram, \& Elefant, 2006; Nordoff \& Robbins, 1977; Simpson \& Keen, 2011; Wigram \& Gold, 2006).

Therapists can attune with the material originating from the child such as rhythmic patterns of movement, expressed and played sounds, dynamic forms of expression and melodic contour. The main role of the therapist is to create the conditions in which reciprocity can develop, then to structure interaction and to promote turn taking, eye contact, joint attention, imitation, engagement/disengagement and other communication functions.

Neuroscience and psychological research support the effectiveness of IMT with children with ASD, investigating how subjects with ASD perceive music and identifying the functional and dysfunctional brain circuits underlying emotional processing of music in autism spectrum disorders (Quintin, Bhatara, Poissant, Fombonne, \& Levitin, 2011; Caria, Venuti, $\&$ de Falco, 2011). Music therapy activity facilitates social, communicative and behavioral skills in young children with ASD, intervening in specific target areas. First, developing imitation skills can increase the child's ability to engage in social interaction (Hobson \& Hobson, 2008; Landa, 2007; Beadle-Brown, 2004). Also, music therapy can increase joint attention ability (Kim 2006; Kim, Wigram, \& Gold, 2008; de Falco \& Venuti, 2006) and reciprocity level (Landa, 2007), as well as affective sharing (Wetherby et al., 2004) and child initiation of interaction (Landa, 2007; Landa, Holman, \& Garrett-Mayer, 2007).

\section{AIM OF THE STUDY}

In this study, we aimed to verify, using observational quantitative measures, the efficacy of IMT treatment in increasing the synchronic ability of children with ASD. There is emerging evidence that music therapy can improve social, communicative and behavioral skills and facilitate regulation ability in children with ASD (Landa, 2007; Beadle-Brown, 2004; Gold et al., 2006). Starting from the observation that ASD symptoms may challenge the development of synchrony and capability of attunement (Johnson et al., 2015; Feldman, 2012), IMT has been introduced for ASD as an adjunctive rehabilitation technique.

We hypothesize that 1) with an IMT protocol of at least twenty sessions, children with ASD significantly improve behavioral and emotive actions as well as synchrony with the therapist, and 2) this improvement persists in different structured contexts.

\section{PARTICIPANTS AND PROCEDURE}

Twenty-five children between the ages of 4 and 6 years $(M=4.82, S D=1.39)$ with autistic disorder (AD) were enrolled as participants. The study was conducted in accordance with ethical principles and for all participants informed consent was obtained from parents.

Participants were recruited among the population of patients at the Observation and Functional Diagnosis Laboratory (ODFLab) at the University of Trento and the Scientific Institute "IRCCS Stella Maris", University of Pisa. ODFLab is a referral center for developmental disabilities, and children and adolescents are brought from across the north of Italy for assessment and treatment; the Scientific Institute "IRCCS Stella Maris" is a suburban university hospital providing tertiary care to patients of all socioeconomic levels.

The absence of identified genetic or medical conditions was verified for all children. Furthermore, all children had no visual or hearing impairments. Multiple diagnostic criteria were used to confirm the presence of autism. Each child received a current clinical diagnosis of autistic disorder according to the Diagnostic and Statistical Manual of Mental Disorders (DSM-IV-TR; American Psychiatric Association [APA] , 2000) criteria, and met full criteria for autism in the Autism Diagnostic Observation Schedule (ADOS Lord, Rutter, DiLavore, \& Risi, 2002). ADOS Modules 1 and 2 were used for all the subjects and all the children passed the cut-off for $\mathrm{AD}$. The mean IQ measured at the age of the diagnosis with the Griffiths Mental Development Scales (Griffiths, 1996) was $72.34(S D=18.92)$; more than half of the children $(60 \%)$ were classified as high-functioning (IQ > 70). In order to eliminate any potential bias, the DSM-IV-TR assessment, the ADOS, and the Griffiths Mental Development Scales were administered by three different trained clinical psychologists. These clinical psychologists were involved only in the diagnostic assessment; they were unaware of the purpose of the study and did not participate in any other phase of this study.

According to the Standardized Autism Diagnostic Observation Schedule scores, which provide a measure of autism severity symptoms, $28 \%$ of our sample consisted of children with mild autistic traits, $56 \%$ consisted of children with moderate autistic traits, and $16 \%$ consisted of children with severe autistic traits.

\section{PROCEDURE}

An observational tool for coding behaviors and emotive states of synchrony Venuti and Bentenuto (2013) 
was applied to video recorded sessions of music therapy with the subject-therapist pairs. For each dyad, we considered the 20 central minutes of the first, tenth and twentieth session of IMT, applying the code to subsequent $15 \mathrm{~s}$ segments (i.e. 80 segments for each session). The duration of IMT sessions was 50 min per week. The same code was applied to the Interactive Section of ADOS (ISA) on 'anticipation of a routine with objects' applied after the $20^{\text {th }}$ session.

Each of the four sessions was coded by two different coders blind to all other information about the dyads. Interrater reliability was established between the coders and was assessed with intra-class correlations and ranged from ICC $=.73$ to .97 with a mean of .80 .

\section{CODE FOR BEHAVIORAL AND EMOTIONAL STATE DURING ADULT-INFANT INTERACTION}

The aim of the code is to quantify synchrony during adult-infant interaction observed during an observational or therapeutic session. Synchrony is the dance of social interaction, and it connects partners working together on a common goal of successful interaction. Synchrony is the simultaneous sharing of affects (or emotions) and behaviors between two partners. The code was developed from the same theoretical construct of the Monadic Phases Manual by Tronick, Als and Brazelton (1980). Our code uses two distinct behavioral and emotional codes because we are treating the atypical ASD condition, while the Monadic code is applied to very young infants with typical development. The code measures the frequency and the quality (positive, negative or neutral) of 4 dimensions essential for synchrony: visual (1. Face expression), auditive (2. Vocalization), postural (3. Direction of the head and 4. Body position), and cinematic (5. Specific movements). Thus five behavioral categories (with an emotional dimension for four of them: $1,2,4,5)$ are coded separately for child and adult in each interval as follows:

Child Behavioral and Emotional status Code [CBEC]:

1. Face expression: direction of gaze (towards the adult, shared object or environment); emotional state as positive (smile, participatory, alert, expression), negative (cry, distress, pout, angry, sad), or neutral.

2. Vocalization: we consider any type of vocal production to adult, object, or self. We evaluate positive (laugh, babbling, positive words or utterance), negative (cry, distress, negative words or utterances) or neutral (echolalia, other sounds) vocalizations.

3. Direction of the head: head as turned to the adult, to other (objects or environment), or to the shared object (instrument or equivalent).
4. Body position: the body is facing the adult, other, or the shared object. Emotional status is positive when the child is leaning, sitting, or standing up near to the shared focus of attention, negative when the child is far away from the shared object, neutral when the body posture is unrelated to the adult or to the shared object.

5. Specific movements: child movements (manipulation, self-manipulation, gestures) are coded as purposeful or purposeless. Emotion is attributed as positive (for imitation, body contact, body gesture with affective and positive valence), negative (purposeless manipulation or removal gestures) or otherwise neutral (no movements).

Adult Behavioral and Emotional status Code [ABEC]:

1. Face expression: direction of gaze (towards the child, shared object or the environment); emotional state as positive (smile, participatory, alert, expression, joyous), negative (cry, distress, pout, angry, sad, kiss, laugh), or neutral.

2. Vocalization: any type of vocal production to child, object or self (e.g. humming). Vocalizations are evaluated as positive (IDS: infant direct speech, modulation of the voice), negative (shout, rapid communication), or neutral.

3. Direction of the head: head is turned to the child, to other, or to the shared object.

4. Body position: the body is facing the child, other, or the shared object. The state is positive when the adult's body is facing towards either the child or the shared object, negative if it is far away from the child or the shared object, neutral if the body posture is unrelated to the child or to the shared object.

5. Specific movements: touch or other manipulation of the child's body, of the shared object, or none of them. The emotion is positive for imitation, body contact, and body gesture with affective and positive valence, negative or purposeless manipulation, or gestures with negative meaning, or neutral (when the adult has no movements).

\section{SYNCHRONY MEASURES}

From the CBEC and ABEC codes, a vector of 9 ternary features ( +1 for positive, 0 for neutral, -1 for negative) was derived for both the child (C) and the therapist (A), from each of the observed 15-second sections. Hence, five behavioral categories and four emotional dimensions were collected for each child $\left(C 1 . B_{\mathrm{i}}, C 1 . E_{\mathrm{i}}\right.$, $C 2 . B_{\mathrm{i}}, C 2 . \mathrm{E}_{\mathrm{i}}, C 3 . B_{\mathrm{i}}, C 4 . B_{\mathrm{i}}, C 4 . E_{\mathrm{i}}, C 5 . B_{\mathrm{i}}, C 5 . E_{\mathrm{i}}$, and similarly for each adult $\left(A 1 . B_{\mathrm{i}}, A 1 . E_{\mathrm{i}}, A 2 . B_{\mathrm{i}}, A 2 . E_{\mathrm{i}}, A 3 . B_{\mathrm{i}}\right.$, $A 4 . B_{\mathrm{i}}, A 4 . E_{\mathrm{i}}, A 5 . B_{\mathrm{i}}, A 5 . E_{\mathrm{i}}$ ), with $i$ ranging from 1 to 80 in correspondence to each 15 -second segment of the 20-minute recordings. These measures were collected at the three different times described before.
Synchrony in music therapy with children with ASD 
We computed the means for the behavioral categories $(\mathrm{CBm}, \mathrm{ABm})$ and the emotional dimensions (CEm, AEm), separately, for both child and therapist.

The obtained measures are now continuous measures ranging from -1 to 1 . A value near to $-1,0$, or 1 indicates a negative, neutral, or positive average behavior/emotion respectively.

In order to account for both the behavioral and the emotional dimensions, the means of the behavioral and the emotional scores for both child and

Paola Venuti, Arianna Bentenuto, Stefano Cainelli, Isotta Landi, Ferdinando Suvini, Raffaella Tancredi, Roberta Igliozzi, Filippo Muratori

therapist were computed: $C m=\frac{(C B m+C E m)}{2}$ $A m=\frac{(A B m+A E m)}{2}$. Furthermore, in order to account for the synchrony between child and therapist, the mean of the two scores was computed, i.e. $A C m=\frac{(C m+A m)}{2}$. In summary, the three synchrony scores (Cm, Am, ACm) were available for each subject at each time point T1 (session 1), T2 (session 10 ), and T3 (session 20), and were considered in the paper.

The same calculations were applied to ISA scores collected at T1 and T3, obtaining, for each subject, an ISA child, an ISA adult, and an ISA synchrony measure.

\section{STATISTICAL METHODS}

Firstly, normality of the measures was assessed using the Shapiro-Wilk test. All variables were found normally distributed $(p>.05)$.

Secondly, to test whether the $\mathrm{Cm}$ and the Am scores differ across the three time points (T1, T2, and T3), we performed pairwise comparisons of the scores applying paired $t$-tests and using the Bonferroni $p$-value adjustment method. This procedure was preferred to the standard $t$-tests given the longitudinal nature of the measures to pair observations at times $t$ and $t+1$. Similarly, we tested whether the means of the synchrony measures (ACm) differ across T1, T2 and T3 by pairwise comparisons with paired $t$-tests and the Bonferroni adjustment.

Moreover, Student's statistics were computed to compare the ISA synchrony score (only available for 18 subjects) and the corresponding ACm score at $\mathrm{T} 3$. Furthermore, in a reduced sample (8 subjects), we investigated differences between synchrony scores at T1 and at T3. Bootstrap Cohen's $d$ effect size measures and their corresponding 95\% confidence intervals (CIs) were reported in the results, in order to account for their validity (Gerlanc \& Kirby, 2015). The number of bootstrap resamples (R) was set at 2000 .

Furthermore, six linear regression models were used to test whether $\mathrm{Cm}$ and $\mathrm{ACm}$ scores at times $\mathrm{T} 1, \mathrm{~T} 2$, T3 could be linearly explained by the age values of the participants, the ADOS scores $(M=5.52$,
$S D=2.04)$, and the IQ scores $(M=72.34, S D=18.92)$ at baseline. The mutual interactions of the independent variables were not considered.

Finally, participants were classified as cognitively "high-functioning" or "low-functioning", based on IQ scores. The 15 subjects with an IQ score greater than 70 were labeled as high-functioning (HF), while the 10 subjects with an IQ score lower than or equal to 70 were labeled as low-functioning (LF). Then, we performed three repeated-measure ANOVAs with $\mathrm{Cm}, \mathrm{Am}$, and $\mathrm{ACm}$ scores as the dependent variables, time as the within-subject factor and cognitive functioning as the between-subject factor. This approach has been developed based on a preliminary data inspection, which suggested a possible non-linear relation between the IMT measures and the cognitive score. Furthermore, the classification of subjects into high/low-functioning is widely used in psychological studies (Burack \& Volkmar, 1992). Moreover, this classification can provide useful insights into the mechanisms that regulate the emotional and behavioral states during IMT sessions.

It is natural to expect that adults' scores will not vary much in relation to both high- and low-functioning subjects, given the different approaches tailored by therapists, whereas the children's scores are likely to show significant differences based on the cognitive profiles. Linear regression models were still fitted in order to investigate the possible linear relations that may have occurred between the child-related synchrony measures (i.e. $\mathrm{Cm}, \mathrm{ACm}$ ) and the other variables related to children, i.e. age, ADOS score, and IQ.

Three subjects were lacking the IMT scores at T2. We imputed these values with the mean values computed for the measures recorded at $\mathrm{T} 1$ and at $\mathrm{T} 3$.

Statistical analyses were performed using R software version 3.3.0 (R Core Team, 2016).

\section{RESULTS}

\section{DESCRIPTIVE DATA}

Standard statistics of the measures from the 25 participants are displayed in Table 1 . The standard statistics of the ISA measures, which were only available for 18 subjects, are reported in Table 2 .

\section{LONGITUDINAL ANALYSIS}

No significant difference was found between the mean of the CBEC-based measure $\mathrm{Cm}$ at $\mathrm{T} 1$ and at $\mathrm{T} 2$, while the difference between the mean of $\mathrm{Cm}$ at T1 and at T3 was found statistically significant, with a moderate effect ( $p=.006$, Cohen's $d=-0.48$, $\mathrm{CI}=(-0.9,-0.07))$, as well as for T2 and T3 $(p=.039$, Cohen's $d=-0.63, \mathrm{CI}=(-0.95,-0.21))$; the mean of 
Table 1

Mean (M) and standard deviation (SD) of scores based on the Child Behavioral and Emotional Code $(\mathrm{Cm})$, Adult Behavioral and Emotional Code (Am), and Synchrony measure (ACm), across times (T1-T3)

\begin{tabular}{lcccccc}
\hline & \multicolumn{2}{c}{$\mathrm{T} 1$} & \multicolumn{2}{c}{ T2 } & \multicolumn{2}{c}{ T3 } \\
\cline { 2 - 7 } & $M$ & $S D$ & $M$ & $S D$ & $M$ & $S D$ \\
\hline $\mathrm{Cm}$ & 0.24 & 0.37 & 0.27 & 0.40 & 0.44 & 0.38 \\
$\mathrm{Am}$ & 0.69 & 0.23 & 0.68 & 0.27 & 0.70 & 0.26 \\
$\mathrm{ACm}$ & 0.46 & 0.26 & 0.47 & 0.31 & 0.57 & 0.30 \\
\hline
\end{tabular}

$\mathrm{Cm}$ scores was progressively increasing from $\mathrm{T} 1$ $(0.24)$ to T2 (0.27) and to T3 (0.44), almost doubling from T1 to T3 (see Table 1).

On the other hand, none the mean comparisons across time of the ABEC-based scores was significant $(p>.100)$.

Furthermore, no significant difference was found between the mean of the synchrony score $\mathrm{ACm}$ at $\mathrm{T} 1$ and at $\mathrm{T} 2$, or between the mean of $\mathrm{ACm}$ at $\mathrm{T} 1$ and at T3 $(p>.100)$. However, the mean of ACm at T3 was significantly greater than the one at $\mathrm{T} 2$, with a moderate effect $(p=.018$, Cohen's $d=-0.55, \mathrm{CI}=(-0.84,-0.17))$. ${ }^{1}$

The mean difference of the ISA synchrony scores and the ACm scores at T3 was not significantly different from zero $(t=.27, d f=25.71, p=.787$, Cohen's $d=0.06, \mathrm{CI}=(-0.45,0.54))$. Finally, the Student $t$-test for paired samples between ISA synchrony scores at T1 and T3 was not significant $(t=-1.21, d f=7, p=.262)$. However, the mean increased from $\mathrm{T} 1 \quad(M=0.49$, $S D=0.25)$ to $\mathrm{T} 3(M=0.58, S D=0.13)$ with a moderate effect size $(-0.43)$ and $\mathrm{CI}=(-1.25,0.40)$. Moreover, the amplitude of the confidence interval at $\mathrm{T} 1(\mathrm{CI}=(0.27$, $0.62))$ is greater than at $\mathrm{T} 3(\mathrm{CI}=(0.46,0.65))$, suggesting that the subjects' synchrony measures tend to conform to higher and less variable values.

\section{LINEAR REGRESSION AND FUNCTIONING FACTOR}

For the linear regression models, none of the variables (chronological age, IQ, severity score) was significant in explaining the $\mathrm{Cm}$ and $\mathrm{ACm}$ scores at T1, T2, and T3 $(p>.100)$. The regression table with estimates is presented in Table 3. Possible multicollinearity between independent variables was ruled out by means of visual inspections and variance inflation factor (VIF) (Fox \& Weisberg, 2011). Indeed, the obtained VIF values were smaller than 3, which is the threshold recommended as the indicator of excessive correlation among regressors (Zuur, Ieno, \& Elphick, 2010).

For the repeated-measure ANOVA with $\mathrm{Cm}$ as the dependent variable, the within-subject factor
Table 2

Mean (M) and standard deviation (SD) of scores of the Interactive Section ADOS (ISA) at time 3 (T3)

\begin{tabular}{lcc}
\hline & \multicolumn{2}{c}{ T3 } \\
\cline { 2 - 3 } & $M$ & $S D$ \\
\hline ISA child & 0.48 & 0.27 \\
ISA adult & 0.59 & 0.09 \\
ISA synchrony & 0.53 & 0.17 \\
\hline
\end{tabular}

"time" was confirmed significant $(F=4.93, p=.011)$. Moreover, a main effect of the functioning factor was found $(F=8.34, p=.008)$, with a stronger effect on HF. Similarly, the repeated-measure ANOVA with ACm as the dependent variable confirmed the within-subject factor "time" as significant $(F=3.32, p=.045)$. Additionally, a main effect of "cognitive functioning" as a between-subject factor was found $(F=6.36$, $p=.019)$, with a stronger effect on HF. As expected, the repeated-measure ANOVA on Am scores did not show any significant factor $(p>.100)$. The different progression of the CBEC-based mean scores associated with $\mathrm{HF}$ and LF individuals, with bootstrapped $95 \%$ CIs $(\mathrm{R}=2000)$, is displayed in Figure 1 . In the figure, the Am mean scores for the therapist are displayed as well, and they remain constant through time (lower in the LF case), as we expected.

In Table 4 the bootstrapped 95\% CIs $(\mathrm{R}=2000)$ for $\mathrm{Cm}$ and Am mean scores are reported.

\section{DISCUSSION}

The main objective of the present study was to verify the efficacy of the IMT to improve and maintain the ability of synchrony in dyads with children with AD. Our results are in agreement with the two general hypotheses.

First, IMT significantly increases the ability of children with ASD to be behaviorally and emotionally connected with the adult in terms of improvement of synchrony after twenty sessions. The higher level of synchrony found at the end of intervention reflects children's greater involvement with the therapist. Indeed, as expected, the adult exhibits the same level of behavioral and emotional engagement over time, while it is the child who increases his competence to be attuned to the adult.

Our observations correspond with the literature suggesting that IMT has the potential to facilitate the skills fundamental to social interaction, especially non-verbal interaction in children with ASD. Music therapists can use "response evoking techniques" that create mutually meaningful and enjoy-
Synchrony in music therapy with children with $A S D$ 


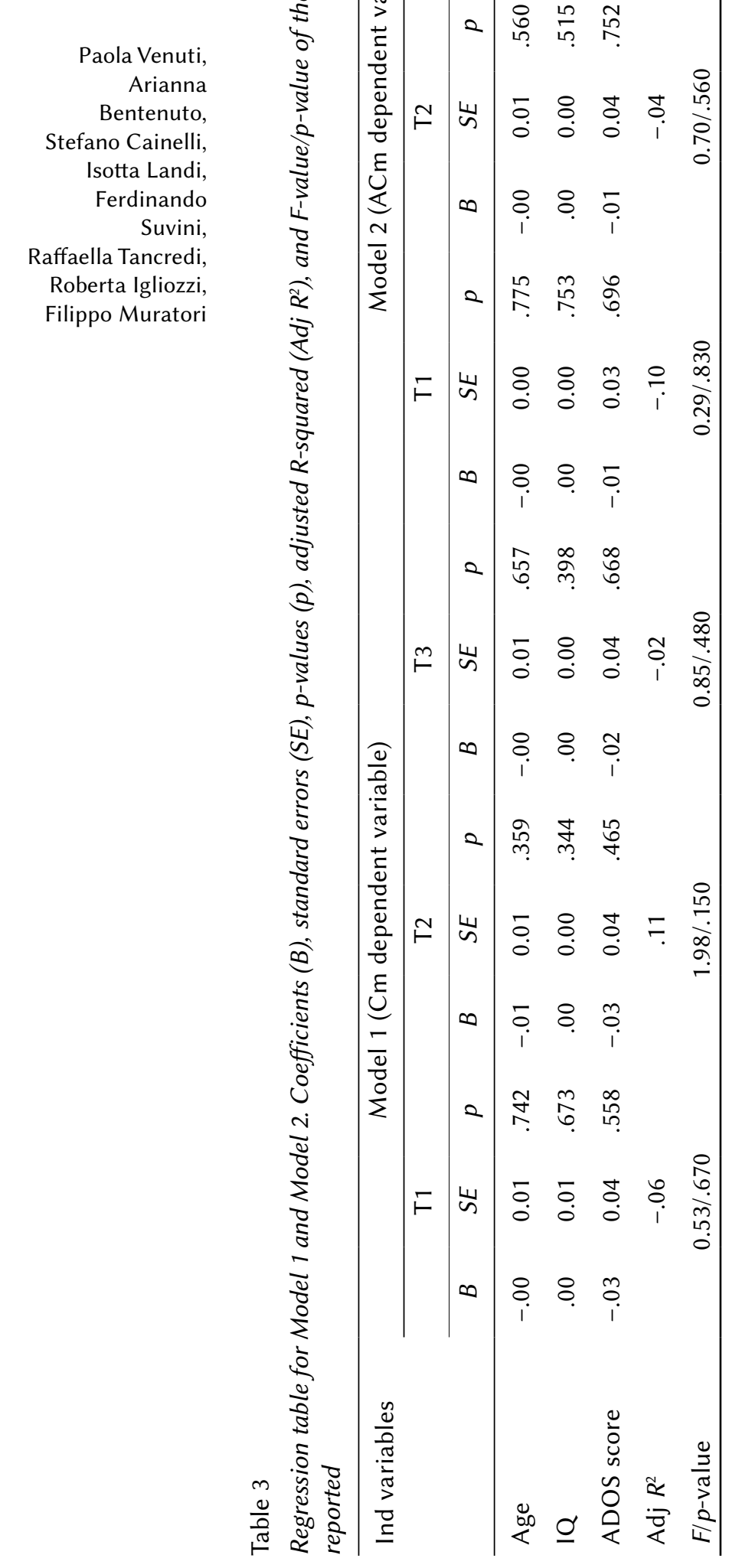

able musical interaction themes in relation to the child's expression and focus of attention (Holck, 2002). By involving the child without requesting an immediate specific response, the therapist creates the opportunity to accept the rhythmic and melodic meanings tuned to his behavior. This strategy progressively leads to the development of synchronous exchanges. Initially, the music therapist mimics the child's action exactly, to create a sensorial calm situation. This "calm attention" (Greenspan \& Wieder, 1999) allows the child to initiate interaction with the therapist and to activate positive emotions and reciprocal emotional exchanges (Kim 2006; Trolldalen, 2005; Wigram \& Elefant, 2008). Such shared context activates synchrony, flexibility and creative reciprocity, which are all restricted in a child with ASD, and which the music therapist seeks to increase (Kim, Wigram, \& Gold, 2008). Several studies have indicated superior gains in joint attention, language development and social communication skills when the adult's behavior remains either contingent or imitative of the child's behavior showing a high level of synchronization and matching during play interaction (Escalona, Field, Nadel, \& Lundy, 2002; Lewy \& Dawson, 1992; Siller \& Sigman, 2002; Watson, 1998). Other case studies have described how IMT results in increased spontaneous eye contact (Bunt, 1994; Plahl, 2000; Saperston, 1973; Robarts, 1996; Gold et al., 2006).

According to the theory that underlines how in the first phase of the treatment the therapist is focused on the creation of an attuned relationship with the child, we have found a significant increase of synchrony between the middle point and the end of the intervention. We could suppose that, after the initial period, the child becomes aware of how to be "in a relation" with the therapist and hence his ability to be synchronous quickly increases. Our findings indicate that, while the therapists' style does not change, children's ability to exhibit behavioral and emotional synchrony increases at the end of the IMT treatment, and it is almost doubled in children who are high-functioning. This result is in line with previous research that evaluated joint attention and positive emotional communication during music therapy compared to play sessions; this research found that children engaged in longer periods of turn-taking and that there were higher and longer durations of 'joy' and 'emotional synchronicity' during music sessions compared to play sessions (Kim et al., 2008, 2009).

Second, the non-trivial accomplishment with children to generalize the acquired ability in a different context was found: in fact, our children showed the same level of synchrony with an unknown adult in the interactive ADOS section as with their therapist. Although we did not find a statistically significant difference between ISA synchrony at T1 and T3 in a reduced sample, we can still observe an increas- 
ing trend between the two time points. Such results suggest that children are able to create a synchronous exchange with a less familiar person, so that it could be suggested that, facilitating simultaneous coordination of 'listening', 'visual referencing', the 'responding' and 'engaging' pattern, music therapy can pave the way for social motivation and social learning in children with autism.

Finally, although chronological age, IQ, and severity of symptoms were not predictive of the quantity of emotional behaviors and synchrony activated during IMT, ANOVA has shown an effect of "cognitive functioning”: in particular high-functioning subjects increase more than low-functioning subjects in building synchrony.

\section{CONCLUSIONS}

Our findings confirm that improvisational music therapy is an efficacious and adequate therapeutic method for improving synchrony in children with ASD. Previous studies have already indicated its utility for increasing joint attention, communication and social skills; these three behavioral features are fundamental for "synchrony", as by improving verbal and non-verbal communication, emotions and joint attention the child can develop dynamic and reciprocal interaction with an adult. Starting from the observational code used in this research, we were able to measure, separately and together, the child's and the therapist's contribution to the synchronic exchange, and we recorded a real increase of the child's ability to use emotional behaviors in a more synchronous way. Further, we have shown that a cycle of twenty sessions of IMT is enough for a child with ASD to have a gain in synchrony and social engagement. Moreover, we have shown that to be high-functioning helps in the adaptation and in the learning of abilities (Mastrogiuseppe, Capirci, Cuva, \& Venuti, 2015; Venuti \& Bentenuto, 2015;

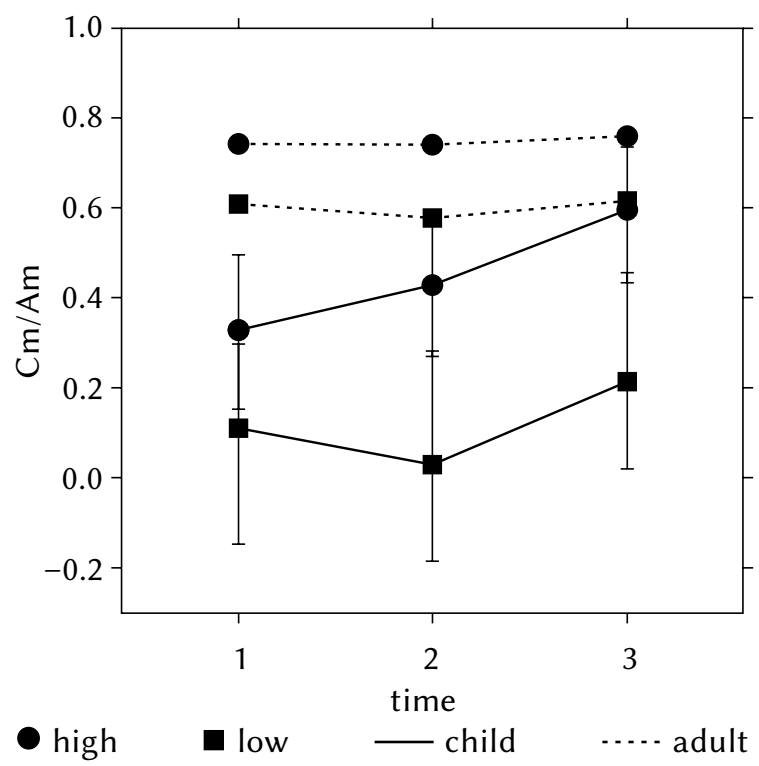

Synchrony in music therapy with children with $A S D$
Figure 1. Progression of child-related $(\mathrm{Cm})$ (solid line) and adult-related (dashed line) mean scores during therapy; scores are shown separately for high- (circles) and low- (squares) functioning subjects (Bootstrapped $95 \%$ Cis, $R=2000$, are displayed for $\mathrm{Cm}$ ).

Quintin et al., 2011), so we could suggest this type of therapy as particularly useful for this subtype of patients with ASD.

Music therapy was until now considered a promising but not yet sufficiently evidenced treatment for improving social interaction and communication skills in children with ASD; our data, although limited by a small sample size, are promising to suggest positive changes in the abilities related to synchronization and social functioning. A limit of our work is the absence of a control sample through which we could demonstrate that the increase of synchrony effectively depends on IMT rather than on the patient-therapist relationship; future research, focused on a comparison between different therapies (e.g. IMT vs. behavioral) applied with similar time sched-

\section{Table 4}

Bootstrap confidence intervals (Cls), with $R=2000$, of the child-related mean scores and the adult-related mean scores, considered separately for high-functioning and low-functioning individuals at T1, T2, and T3

\begin{tabular}{lccc}
\hline & \multicolumn{3}{c}{ Cls of CBEC-related mean scores } \\
\cline { 2 - 4 } & $\mathrm{T} 1$ & $\mathrm{~T} 2$ & $\mathrm{~T} 3$ \\
\hline High-functioning & $(0.15,0.49)$ & $(0.27,0.58)$ & $(0.43,0.73)$ \\
Low-functioning & $(-0.15,0.30)$ & $(-0.18,0.28)$ & $(0.02,0.45)$ \\
\hline & & Cls of ABEC-related mean scores & $\mathrm{T} 3$ \\
\cline { 2 - 4 } & $\mathrm{T} 1$ & $\mathrm{~T} 2$ & $(0.61,0.84)$ \\
High-functioning & $(0.61,0.83)$ & $(0.59,0.82)$ & $(0.42,0.75)$ \\
\hline
\end{tabular}


ules could improve our knowledge on specific effects of music therapy in children with ASD.

\section{ACKNOWLEDGMENTS}

We gratefully acknowledge the contribution of parents and children who participated in this study. We thank Cesare Furlanello for his support.
Paola Venuti,

Arianna

Bentenuto,

Stefano Cainelli, Isotta Landi, Ferdinando Suvini, Raffaella Tancredi, Roberta Igliozzi, Filippo Muratori

\section{ENDNOTE}

1 The $p$-values already account for the Bonferroni correction; indeed the $p$-values have been multiplied by three (number of comparisons), by design of the $\mathrm{R}$ function pairwise $t$ test (R Core Team, 2016).

\section{References}

American Psychiatric Association (APA). (2000). Diagnostic and Statistical Manual of Mental Disorders. Fourth Edition, Text Revision (DSM-IV-TR). Washington, D.C.: APA.

Ainsworth, M. D. S., Bell, S. M., \& Stayton, D. J. (1974). Infant-mother attachment and social development: "Socialisation" as a product of reciprocal responsiveness to signals. In M. P. M. Richards (ed.), The integration of a child into a social world (pp. 99-135). New York: Cambridge University Press.

Alvin, J. (1978). Music therapy for the autistic child. London, UK: Oxford University Press.

Baker, J. K., Messinger, D. S., Lyons, K. K., \& Grantz, C. J. (2010). A pilot study of maternal sensitivity in the context of emergent autism. Journal of Autism and Developmental Disorders, 40, 988-999.

Baker, J. K., Fenning, R. M., Howland, M. A., Baucom, B. R., Moffitt, J., \& Erath, S. A. (2015). Brief Report: A Pilot Study of Parent-Child Biobehavioral Synchrony in Autism Spectrum Disorder. Journal of Autism and Developmental Disorders, 45, 4140-4146.

Beadle-Brown, J. (2004). Elicited imitation in children and adults with Autism: the effect of different type of actions. Journal of Applied Research in Intellectual Disabilities, 17, 38-48.

Belsky, J., Rovine, M., \& Taylor, D. G. (1984). The Pennsylvania Infant and Family Development Project: III. The origins of individual differences in infant-mother attachment: Maternal and infant contributions. Child Development, 55, 718-728.

Black, B., \& Logan, A. (1995). Links between communication patterns in mother-child, father-child, and child-peer interactions and children's social status. Child Development, 66, 255-271.
Bornstein, M. H., \& Lamb, M. E. (2015). Developmental science: An advanced textbook ( $7^{\text {th }}$ ed.). New York, NY: Psychology Press.

Bunt, L. (1994). Music therapy, an art beyond words. London: Routledge.

Burack J. A., \& Volkmar F. R. (1992). Development of low and high functioning in autistic children. Journal of Child Psychology and Psychiatry, 33, 607-616.

Caria, A., Venuti, P., \& de Falco, S. (2011). Functional and dysfunctional brain circuits underlying emotional processing of music in autism spectrum disorders. Cerebral Cortex, 21, 2838-2849.

Cole, P. M., Hall, S. E., \& Radzich, A. M. (2009). Emotional dysregulation and the development of serious misconduct. In S. L. Olson \& A. J. Sameroff (eds.). Biopsychosocial regulatory processes in the development of childhood behavioral problems (pp. 186-211). New York, NY, US: Cambridge University Press.

Dawson, G. (2008). Early behavioral intervention, brain plasticity, and the prevention of autism spectrum disorder. Development and Psychopathology, 20, 775-803.

De Falco, S., \& Venuti, P. (2006). "E' possibile aumentare l'attenzione condivisa in soggetti con disturbo dello spettro autistico?" [Is it possible to improve the joint attention in individuals with autism spectrum disorder?]. Giornale Italiano delle Disabilitŕ, 6, 14-27.

Dumas, G., Nadel, J., Soussignan, R., Martinerie, J., \& Garnero, L. (2010). Inter-brain synchronization during social interaction. PLoS One, 5, e12166e12166.

Edgerton, C. L. (1994). The effect of improvisational music therapy on the communication behaviors of autistic children. Journal of Music Therapy, 31, 31-61.

Escalona, A., Field, T., Nadel, J., \& Lundy, B. (2002). Brief report: Imitation effects on children with autism. Journal of Autism and Developmental Disorders, 32, 141-144.

Feldman, R. (2012). Parent-Infant Synchrony: a biobehavioral model of mutual influences in the formation of affiliative bonds. Monographs of the Society for Research in Child Development, 77, $42-51$.

Fox, J., \& Weisberg, S. (2011). An R Companion to Applied Regression ( $2^{\text {nd }}$ ed.). Thousand Oaks CA: Sage. URL: http://socserv.socsci.mcmaster.ca/jfox/ Books/Companion.

Geretsegger, M., Holck, U., Carpente, J. A., Elefant, C., Kim, J., \& Gold, C. (2015). Common characteristics of improvisational approaches in music therapy for children with autism spectrum disorder: developing treatment guidelines. Journal of Music Therapy, 52, 258-281. doi: 10.1093/jmt/thv005

Geretsegger, M., Elefant, C., Mössler, K. A., \& Gold, C. (2014). Music therapy for people with autism 
spectrum disorder. Cochrane Database of Systematic Reviews, 17, CD004381.

Geretsegger, M., Holck, U., \& Gold, C. (2012). Randomised controlled trial of improvisational music therapy's effectiveness for children with autism spectrum disorders (TIME-A): study protocol. BMC Pediatrics, 12(1), 2.

Gerlanc, D., \& Kirby, K. (2015). bootES: Bootstrap Effect Sizes. R package version 1.2. https:// CRAN.R-project.org/package $=$ bootES

Gold, C., Wigram, T., \& Elefant, C. (2006). Music therapy for autistic spectrum disorder (Cochrane Review). The Cochrane Library, 2.

Greenspan, S. I., \& Wieder, S. (1999). A functional developmental approach to autism spectrum disorders. Research and Practice for Persons with Severe Disabilities, 24, 147-161.

Griffiths, R. (1996). Griffiths Mental Development Scales. Firenze: Organizzazioni Speciali.

Harrist, A. W., \& Waugh, R. M. (2002). Dyadic synchrony: Its structure and function in children's development. Department of Human Development and Family Science, 22, 555-592.

Hughes, M. H. (1995). A comparison of mother-infant interactions and the client-therapist relationship in music therapy sessions. In T. Wigram, B. Saperston, \& R. West (eds.), The art \& science of music therapy: A handbook (pp. 296-308). The Netherlands: Harwood Academic Publishers.

Hobson, R. P., \& Hobson, J. A. (2008). Dissociable aspects of imitation: A study in autism. Journal of Experimental Child Psychology, 101, 170-185.

Holck, U. (2002). Music therapy for children with communication disorders. In T. Wigram, I. N. Pedersen, \& L. Bonde (eds.), A comprehensive guide to music therapy (pp. 183-187). London: Jessica Kingsley Publishers.

Holck, U. (2004a). Interaction themes in music therapy-definition and delimitation. Nordic Journal of Music Therapy, 13, 3-9.

Holck, U. (2004b). Turn-taking in music therapy with children with communication disorders. British Journal of Music Therapy, 18, 45-54.

Johnson, M. H., Jones, E. J. H., \& Gliga, T. (2015). Brain adaptation and alternative developmental trajectories. Development and Psychopathology, 27, 425-442.

Kasari, C., Gulsrud, A. C., Wong, C., Kwon. S., \& Locke, J. (2010). Randomized controlled caregiver mediated joint engagement intervention for toddlers with autism. Journal of Autism and Developmental Disorders, 40, 1045-1056.

Kim, J. (2006). The effects of improvisational music therapy on joint attention behaviors in children with autistic spectrum disorder. Unpublished Ph.D thesis. Denmark: Aalborg University.

Kim, J., Wigram T., \& Gold, C. (2008). The effects of improvisational music therapy on joint attention behaviors in autistic children: a randomized controlled study. Journal of Autism and Developmental Disorders, 38, 1758-1766.

Kim, J., Wigram, T., \& Gold, C. (2009). Emotional, motivational and interpersonal responsiveness of children with autism in improvisational music therapy. Autism, 13, 389-409.

Landa, R. (2007). Early communication development and intervention for children with autism. Mental Retardation and Developmental Disabilities Research Reviews, 13, 16-25.

Landa, R. J., Holman, K. C., \& Garrett-Mayer, E. (2007). Social and communication development in toddlers with early and later diagnosis of autism spectrum disorders. Archives of General Psychiatry, 64, 853-864.

Leclère, C., Viaux, S., Avril, M., Achard, C., Chetouani, M., Missonnier, S., \& Cohen, D. (2014). Why synchrony matters during mother-child interactions: a systematic review. PLoS One, 9, 1-34.

Lewy, A. L., \& Dawson, G. (1992). Social stimulation and joint attention in young autistic children. Journal of Abnormal Child Psychology, 20, 555-566.

Lord, C., Rutter, M., DiLavore, P.C., \& Risi, S. (2002). Autism Diagnostic Observation Schedule. Los Angeles: Western Psychological Services.

Maccoby, E. E., \& Martin, J. A. (1983). Socialization in the context of the family: Parent-child interaction. In E. M. Hetherington \& P. H. Mussen (eds.), Handbook of child psychology: Vol. 4. Socialization, personality, and social development (pp. 1-87). New York: Wiley.

Mastrogiuseppe, M., Capirci, O., Cuva, S., \& Venuti, P. (2015). Gestural communication in children with autism spectrum disorders during mother-child interaction. Autism, 19, 469-481.

Nordoff, P., \& Robbins, C. (1977). Creative music therapy. New York: John Day Company.

Pavlicevic, M. (1997). Music therapy in context; music, meaning and relationship. London: Jessica Kingsley Publishers.

Plahl, C. (2000). Entwicklung Fo"rdern durch Musik. Evaluation Musiktherapeutischer Behandlung [Development through music. Assessment of music therapy treatment]. Unpublished Ph.D thesis, 1999. Münster: Waxman.

Quintin, E. M., Bhatara, A., Poissant, H., Fombonne, E., \& Levitin, D. J. (2011). Emotion perception in music in high-functioning adolescents with autism spectrum disorders. Journal of Autism and Developmental Disorders, 41, 1240-1255.

R Core Team. (2016). R: A language and environment for statistical computing. $R$ Foundation for Statistical Computing, Vienna, Austria. URL https://www.R-project.org/

Robarts, J. Z. (1996). Music therapy for autistic children. In C. Trevarthen, K. Aitken, D. Papoudi,
Synchrony in music therapy with children with $A S D$ 
\& J. Robarts (eds.), Children with Autism: Diagnosis and interventions to meet their needs (pp. 132-160). London: Jessica Kingsley Publishers.

Siller, M., \& Sigman, M. (2002). The behaviors of parents of children with autism predict the subsequent development of their children's communication. Journal of Autism and Developmental Disorders, 32, 77-89.

Siller, M., \& Sigman, M. (2008). Modeling longitudinal change in the language abilities of children
Paola Venuti,

Arianna Bentenuto, Stefano Cainelli, Ferdinando Suvini, Raffaella Tancredi, Roberta Igliozzi, Filippo Muratori Isotta Landi, with autism: parent behaviors and child characteristics as predictors of change. Developmental Psychology, 44, 1691-1704.

Simpson, K., \& Keen, D. (2011). music interventions for children with autism: narrative review of the literature. Journal of Autism and Developmental Disorders, 41, 1507-1514.

Saperston, B. (1973). The use of music in establishing communication with an autistic mentally retarded child. Journal of Music Therapy, 10, 184-188.

Stern, D. N. (1985). The interpersonal world of the infant: A view from psychoanalysis and developmental psychology. New York: Basic Books.

Trolldalen, G. (2005). Sharing through affects: The role of 'affect attunement' in musical improvisation. Unpublished paper presented at the $11^{\text {th }}$ World Congress of Music Therapy, Brisbane, Australia.

Tronick, E. Z., Als, H., \& Brazelton, T. B. (1977). Mutuality in mother-infant interaction. Journal of Communication, 27, 74-79.

Tronick, E. Z., Als, H., \& Brazelton, T. B. (1980). Monadic Phases: a structural descriptive analysis of infant-mother face to face interaction. Merrill Palmer Quarterly of Behavior and Development, 26, 3-24.

Venuti, P., \& Bentenuto, A. (2013). Manual of Code for behavioral and emotional state during adult infant interaction. Unpublished Manuscript.

Venuti, P., \& Bentenuto, A. (2015), Intervento precoce ed intensivo con i bambini con ASD: come cambia il profilo di sviluppo? Oral presentation to the Conference: "Autismo: trasformazioni possibili in rapporto all'etŕ e ai sottotipi clinici" [Early and intensive intervention for children with ASD: How to change the developmental profile]. Rome, October 2015.

Volkmar, F., Siegel, M., Woodbury-Smith, M., King, B., McCracken, J., \& State, M. (2014). Practice parameter for the assessment and treatment of children and adolescents with autism spectrum disorder. Journal of the American Academy of Child and Adolescent Psychiatry, 53, 237-257.

Watson, L. R. (1998). Following the child's lead: Mothers' interaction with children with autism. Journal of Autism and Developmental Disorders, 28, 51-59.

Wetherby, A. M., Woods, J., Allen, L., Cleary, J., Dickinson, H., \& Lord, C. (2004). Early indicators of au- tism spectrum disorders in the second year of life. Journal of Autism and Developmental Disorders, 34, 473-493.

Wigram, T., \& Gold, C. (2006). Music therapy in the assessment and treatment of autistic spectrum disorder: clinical application and research evidence. Child: Care, Health and Development, 32, 535-542.

Wigram, T., \& Elefant, C. (2008). Therapeutic dialogues in music: Nurturing musicality of communication in children with autistic spectrum disorder and Rett syndrome. In C. Trevarthen \& S. Malloch (eds.), Communicative Musicality (pp. 423-446). Oxford: Oxford University Press.

Zuur, A. F., leno E. N., \& Elphick, C. S. (2010). A protocol for data exploration to avoid common statistical problems. Methods in Ecology and Evolution, 1, 3-14. 